海作酒問題的研究，(8) 長波的研究，（9）若 干区域海陆过渡地帶地球內部構浩的研究，(10) 北梅和南極区域的水文气象狀况。

3. 覌測规韭及仪器标准問題: 为了保証全球 性观測計划的統一，以及 “同时覌測”所得的記 录富有比較性, 不能不在覌測叟氾和仪器标准方

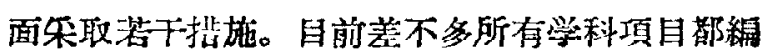
制了覌測手加，对于观測程序，通用符号等等，都

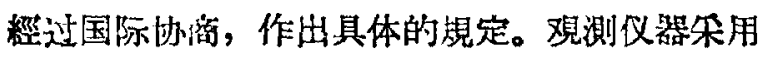
妥羓的国际标准, 也是十分重要的事。在气象学 方面，国际地球物理年东欧区域会議曾挸定气压 仪器以列宁格勒地球物理观象总台的气压表为标 推, 耐輻射观測仪器, 則以德国波苂坦为标准。才 家所熟知的探空称綫电气象仪，現在世界上已有 14和不洞的型式，因此国际間有必要相互进行比 較，期做观测結果能够有效使用。其他各学科的 覌測仪器往徍比气象仪器更为特殊与精管, 因此 世要求国际上統一的标准。

4. 讬界日：为了获得大望的全球“同时覌測”

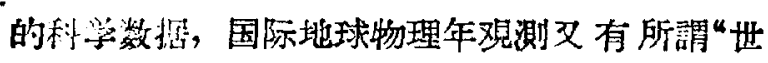
界日”的思定。其中文分正規的、特殊的和气象

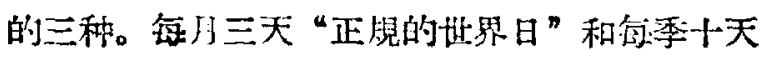
的“世界气像覌測时間”(或簡称为“世界旬”)均为

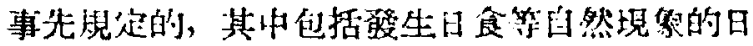

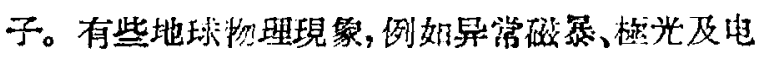

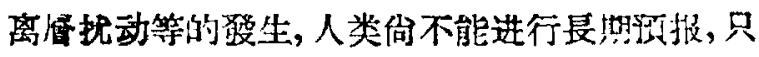
能在几天或几小时以前由中心預报机样临的琶出 准备进行观測的“警报”，林規定“特殊世界观测期 間”，以便利全球各地在同时加品各項目的观胃测。

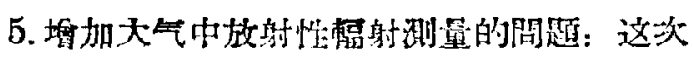
在巴落隆那为这問题單独成立了一个工作小維。

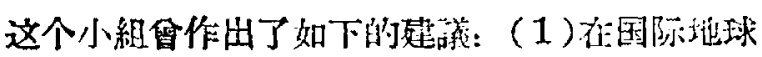
物理年內进行全世界性的观測，测盗空气、降水

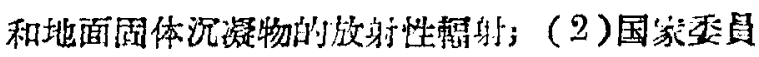
会莧集資料，以便利于样品的分析；（3）設立一

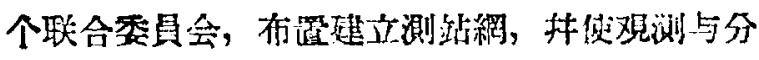
析方法标准化。

6. 設证世招資料中心問題：通过国际地球物

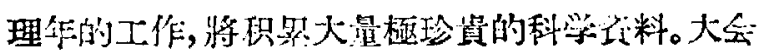

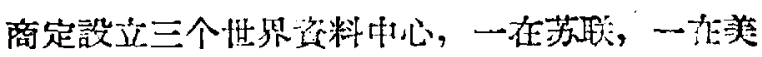
国，另一个按不同学科分設在各地。所有参加国际 地球物理年的国家，有义务由国家委員会急集自

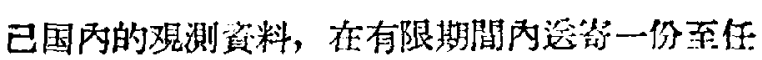
自选定的某一个世界琹料中心。世界资料中心則

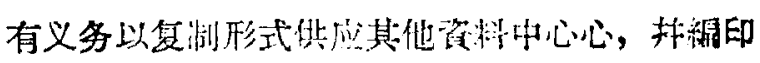
資料目录，供应各国科学机模。

\title{
参加苏联磁現象物理学会竡报告・
}

\author{
葛庭粆
}

(中国科学院金国明㠰所)

苏联科学院物理学数学部和莫斯科大学联合 召开的磁現象物理学会翊从5月23日到31日在莫

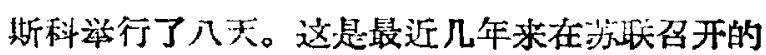
第三次磁等会議。前雨次公議是 1946 年 12 月和 1951年11月在斯稚尔德洛夫斯克城（苏联科学院 烏拉尔分院金等物理研究所的所在地）召开的。 这次会議和以前丽次不同，除去荕联科学家以外， 应邀加的还有中国、波蘭、捷克斯洛伐克、德 模志民主去和国、匈牙利、印度、日本、美国、 英国、法国、话籣等国的科学家約 30 人。中国出

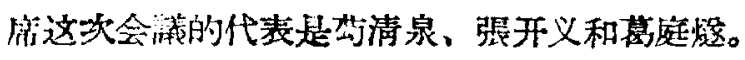

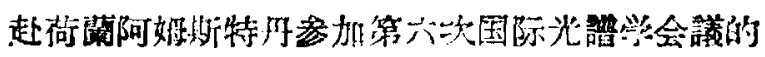

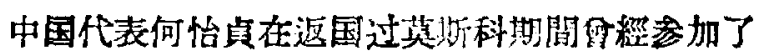
一部分的会議和参覌。

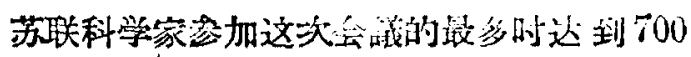

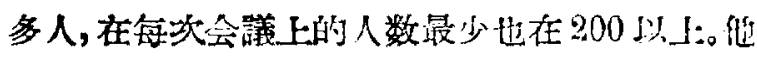
們来自20各个不同的城古，其中有磁学物理的家、 电气工程师、理諭物望学家和金屬学家，代表著

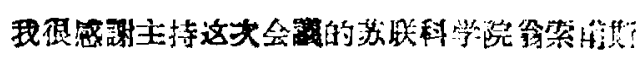

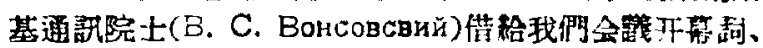

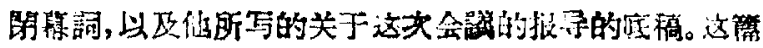

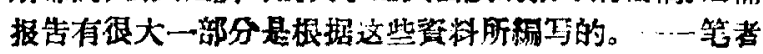


苏联科学选和备加盟共和国科学院的研究單位、 各工莱部閒、厂的企業和高等学校。

\section{一 会議的学术内容}

会議的內容很广誌，报告相討論了与磁現象 特理学有关的各个方面，包括理論、实驗和技术 方面，所联系的科学領域有理論物理、低演物理、 牛导佮、电子学、光学、金匴学和金感物理。在 所作的 80 几个报告当中，参加会翣的外国科学家 們一共作了 20 个报告。

首次会議是在莫斯科大学的大礼堂美行的。

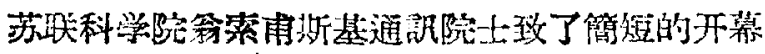
詞。他指出: “在自然現象中，物質的磁性占有極 其广閣的領域。一方西，物留的最細微形态（基 本粒子）具有磁性，另一方面，在星际空間的磁 場对于宇宙的生命起着重要的作用。问时，已敉 揭路了的关于物算磁性的咇室給我們打开了在技 术上实际应用的广閶前涂。因而, 关于磁現象物 理学的問題是非常众多的，在这次会議上只能报 告和討諭磁学中最重要部閏的几个問題。这可以 分为四个方面: 1. 弱磁性物暂的磁性和低温磁

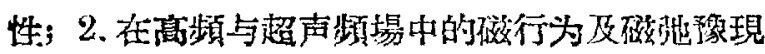
像；3. 鉄磁态和反鉄磁态物理学；4. 技术䂭化曲 和硫性材料物理学。”

以后的全体会和分組会分别在苏联科学院列 別挺大物理研究所和暮斯科大学物理楼大数空内 举行。

\section{1. 弱磁性物筫的硫性和低温磁性}

在砇現象物理学当前登的阶段，关于弱磁 性物質的磁性和低治磁性方面流有兴趣的研究是 磁化稺随着磁場强度的不同而發生的起伏性变化 （德哈斯一范阿耳荪数应）以及磁場电效应（电 阻在磁場中的变化和霍耳效应）。研究这些現致能

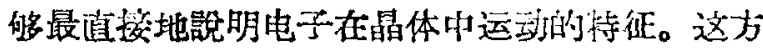

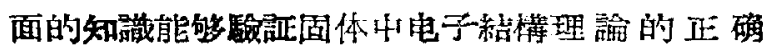
性，也能够建立一个更点实的理洨模型，以計算 晶体中的电子能㪘。

在开幕詞上后，哈尔科夹的維尔金 (Б. H. Bop-

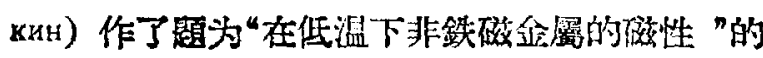
报告。这个报告总結了鼠克麗热和国科学院物理 技术研究所在1949-1955这个期間內关于这方面 所作的一系列实驗工作。由于研究了一采列金䙓
單晶体的磁性的結果，他們指出，所調的德合淤一

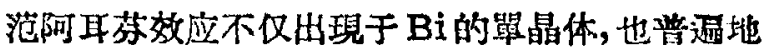
出現于許多其它的金属晶体。把实騟結果与根招 自由电子模型所推导的理論作比較，可以确定标 志着金屬中电子态的基本参最。进一步的实駸更

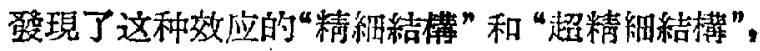
即發現了磁化筷随着磁場而發生的“周期性”变化

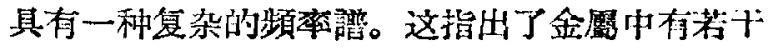

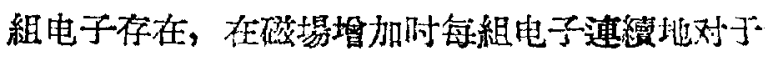
德哈斯一范阿尔萑效应作出黄献, 也指出了有可

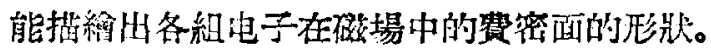

英国劍桥的学者非具尔欮授 (D. Shoenberg）用㥇語作了 “德哈斯一氾阿尔苏效应的区 域的实驗研究”的报告。他指出, 在弱磁場下进行 測量时仅与费嘧西的一小部分强生关添，因而只 能得到資密面的“精細結構”。要得到关于大部分 的費密面的知識必須用較大的磁場(約为 $10^{5}$ 奥断 特)。作者設計了新的測星方法, 可以在陰極射

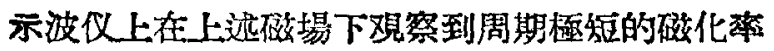
“振萿”。

哈尔科夫的包罗維克 (E. C. Bоровик) 在“磁

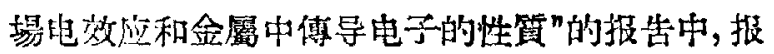
导了在位湿下同时研究霍耳效应和电阻在䂭場中

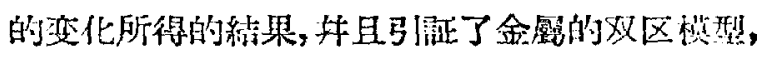
認为电导是由于雨类具有流动性的算点 (“空究” 和电子）所闰时引起来的。这种“管分”和计广有 好几䋊，分男其有不同的流动性。莫斯科阳阿列

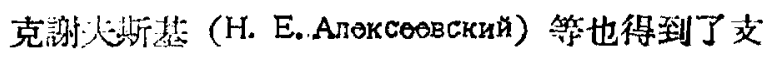

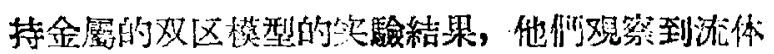

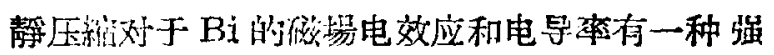
烈的可迹作成。

哈尔科头的丝甫西茨（И. М. Лифшuи) 队其

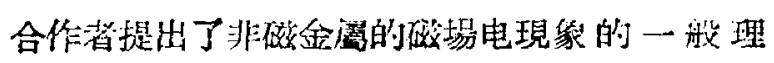

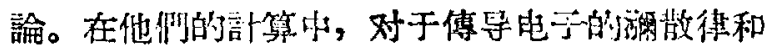

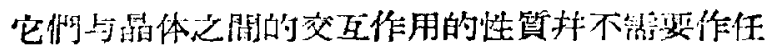

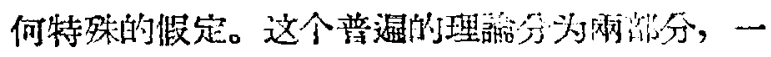
部分是經典的，一部分是量考力学的。作为运項 工作的一部分，青年工作都阿茲则耳（M. Я. А3-

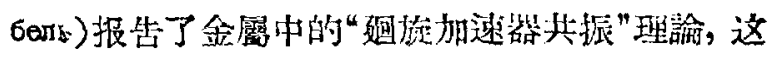
种其振是在融頻电磁埸及不变磁場的共同作用下 所产生的。从金撃电諭的最一般的假設出發, 报告㨋指出了这种共振与文䰚中所叙选的牛导体 
中织的共振有本質上的区別，根据这种妓应的研 究可以得出全第中电子的能墙的有用知識。

关于金第电于䠼的理論研究方面, 还有日本 东京大学青年数投久保完五 (Ryogo Kubo)“在 强㗀场下金的磁場电效应理諭”和哈尔科夫

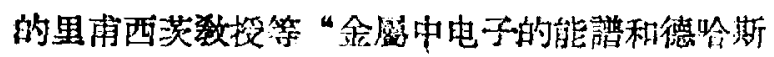
一沦阿尔落效应”的报告。

有三篇报告是关于牛导你的磁性的。列宁格

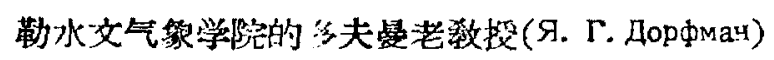
报告了“关于牛导体的磁化爽的个别組 分的測

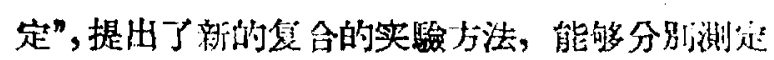

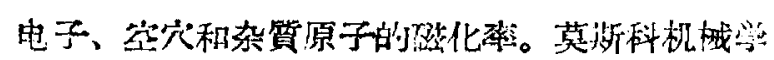
院基科因院士（K，K. Кико: 的蓝向光磁效应”的报告, 这是一个很有兴趣的新 現缘，磁場提度、温度、照度对于这种效应具有

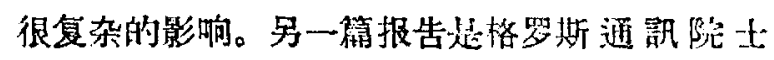

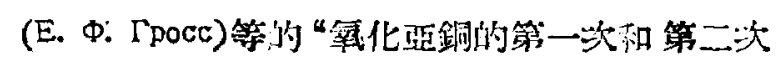
等昆效应以及激“的抗磁性”。

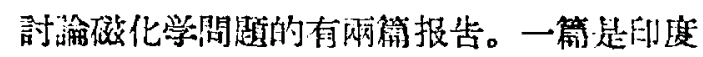

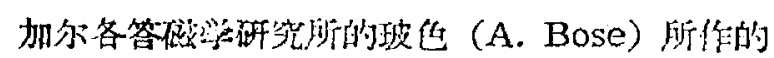

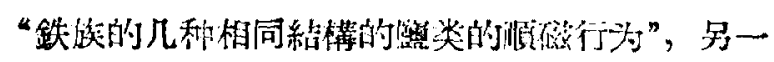
篇是多夫是所作的“抗磁化合物的磁化学及極化

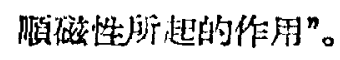

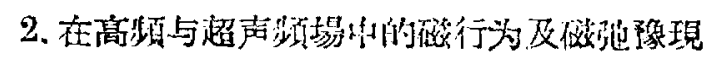
参

这方面的研管具得很大的学求上和实用上的 新义，由此可以樭到关于电于在子、分子以及

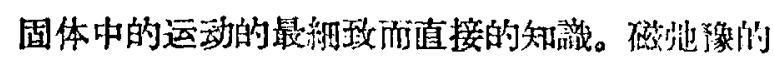
方法已䌌在物理学和化学的各个領域中得到了\% 没的实际应用。如同上迅的磁埸电效应一椾，话

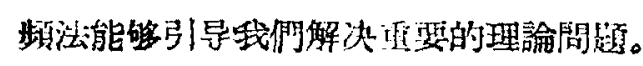

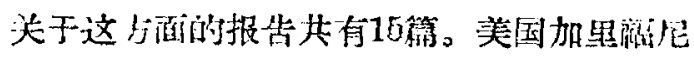
留大学的奇普转涭 (A. F. Kip) 首先报告了“阔 体中的“迴疑加速器”共振和䈏地三人 (plasma)

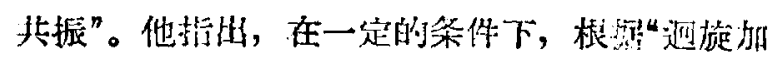

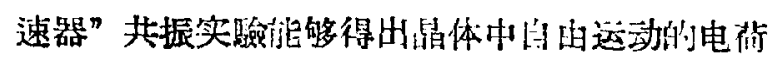

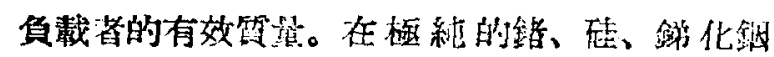
(indium antimonide), 以及一些 Ge-Si 合金

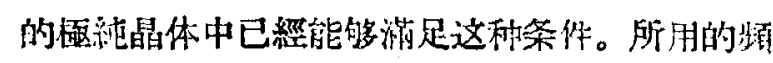
幽海国是 $9,000-60,000 \mathrm{mc} / \mathrm{s}$, 温度接近于- $4^{\circ} \mathrm{K}$ 。 此外，作者又在 $\mathrm{n}$ 型的徐化銅留体中覌察到一

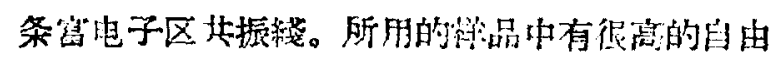

电于管度 $\left(\sim 10^{14} / \mathrm{cm}^{8}\right)$, 是由杂算原子所引趝 来的。这种高䈨度已䅔足以强烈地拢乱“迥施加 速器”共振，因而能够进行一些察电子区步振效应 的实驗研究。

荷闌策顿大学的戈特教提 (C. J. Gorter) 接着报告了“順磁㱜豫項域中的新展”。莫洛托 夫的沙波什尼科夫 (H. Г. Шалошников) 报告了 “傾磁弛像的現象性的理論”。

有三等报告是关于在各种物的原子核步 振和电子共振的一些具体閣题的, 这些研究的維:

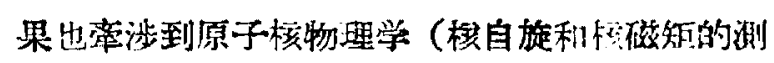
点声和磁化学。

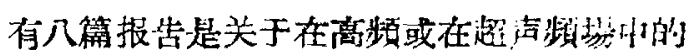

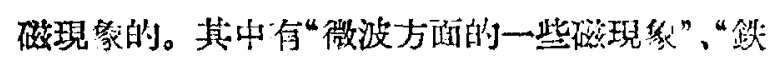

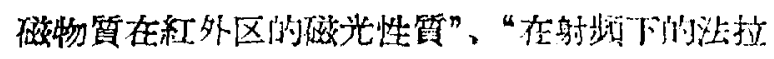

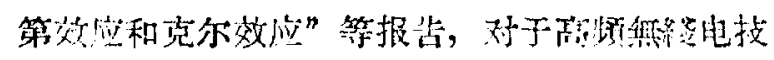

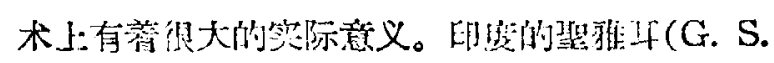

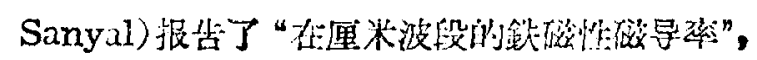

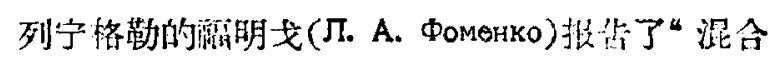

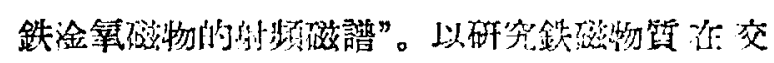

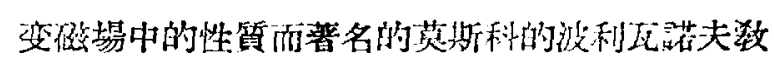
授 (К. М. Попиванов)在这次会放中与他的合作者

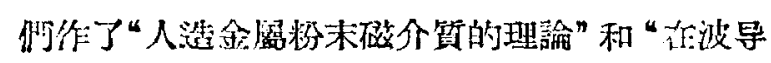

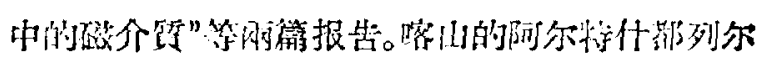

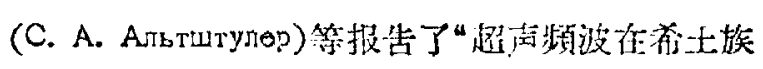

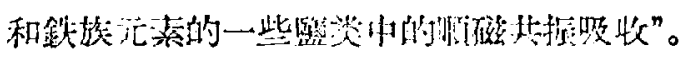

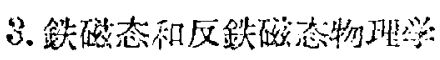

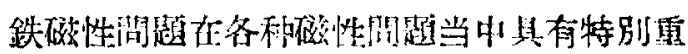

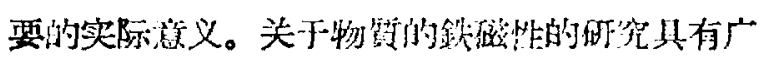

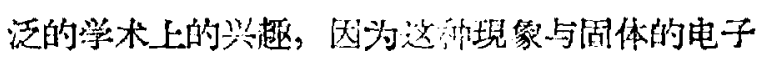

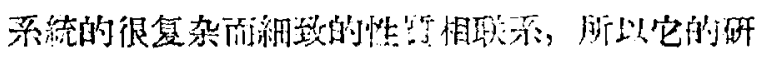

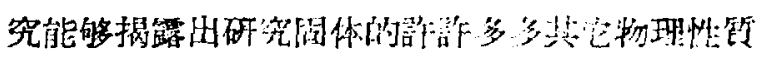

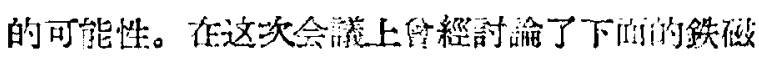

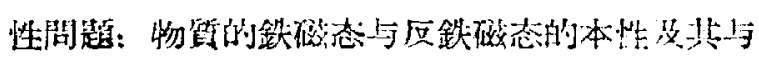

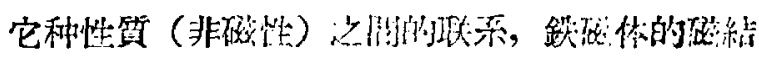

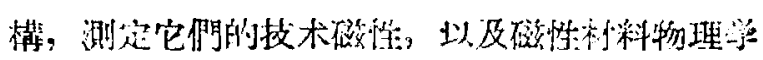
等問題。

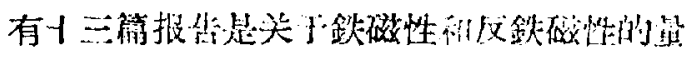
子力学理拥的。

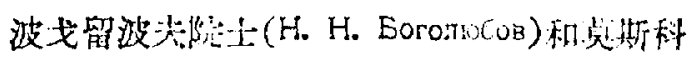

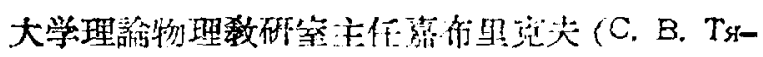

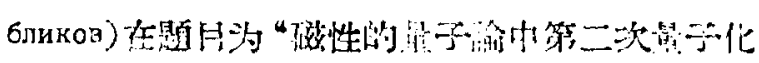


的近似法”的报告中許还了他們的一柔列的关于

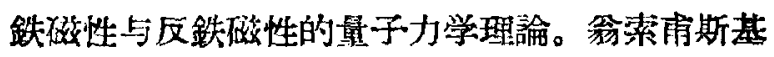

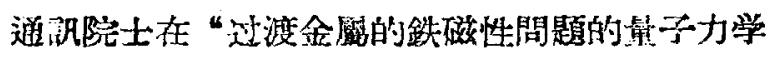
处理”的报告中济述了斯維尔德洛夫斯克(鸟拉尔 分院金屬物理研究所) 的理論物理学工作当关于 过㳊元素鼠体的量子諭的研究成果。过渡元素昆 体具有兩个分支的电子能譜，一个是自旋波（铁 磁子) 的 (玻色的)，一个是傅焈电子的(費密 的)。他指出，在过渡元䇣晶体的棏形下，可以应 用一种混合的表像方式, 用布洛新的集体缉电子 函数（集体电子理諡）来描迌价电子，用原子

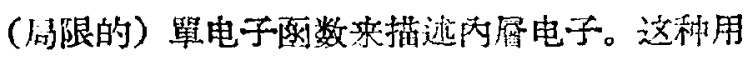
千过渡元溸晶侪的杂拼的 (s-d) 模型可以导出 电于和离于采統的准筫点的能譜的各个分支, 块

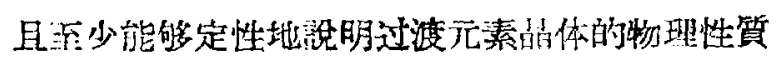

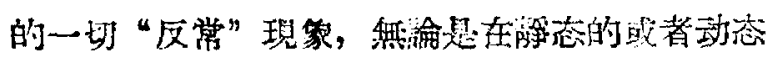
的。

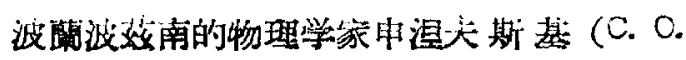
山еневския)报告了“关于自旋波理諭的訴庇”，民 主德国的物理学家盖柏 ( $\Gamma$. Г 旋波的統計法”。

在鉄磁理諭方面还有 “非完美昆体的鉄磁理 諭”、“傅导电子的鉄磁性”等提告。唗克斯洛伐

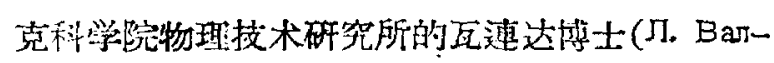

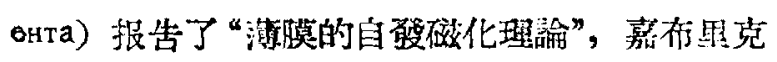
夫等报告了“磁各向开性常数的温度的和磁埸的 化賴关秀”。

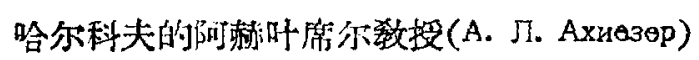
在題目为 “在低海下鉄电分体中的动力过程和弛 理理論”的报占中，假定鉄电介体代表兩种元激

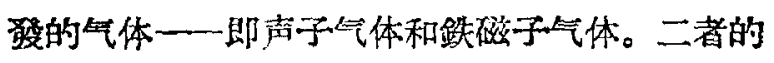
交互作用对于鉄电介体的热导鿟以及鉃电介体中 的声吸收現象（跌声共振和独声振落）都具有决 资性的作用。另一䇾报告是斯維尔德洛夫斯克的 圖罗夫(E. A. Typo日) 的 “关于元激發的譜与鉄琉 昆体中的一些动力过程”。

莫斯科的金茹布尔格(B. Л. Гинзбург) 在“关 于超导的鉄磁体”的报告中指出，自發磁化使我 們难以查知鉄磁体的超导性，但是用薄膜或者用 具有高的稪項磁力的較大样品, 在某种情形下有 可能覌祭到鉄磁金屬和合金的招导性。

在另一系列的报告中討論了鉄磁性和反鉄磁
性物筫的热力学，也討淪了它們的基本性質与温 度的体賴关係。这方面的报告共有12篇, 其中包 括荷耚物理学家戈特和法国物理学家 奈 尔 (L. Néel) 以及美国培尔电話实验空的物理举家包佐 尔茲 (R. M. Bozorth)等的报告。

戈特新授在他的报告 “关于反铁磁性的热力

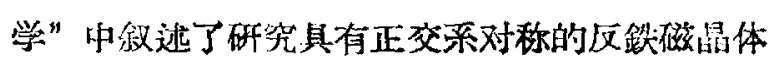
的 $\mathrm{H}$ 一 $\mathrm{T}$ 相圖所得的結果。指出在华衡嫣中有雨

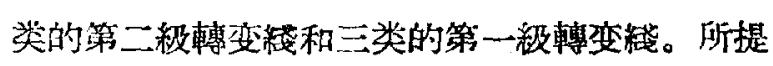
出的理諭与与实驗很相合。奈尔接授作了爾筒报告: “在临闻磁場中的变磁体或抏鉄磁体”、“新型的鉄

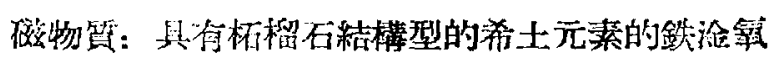

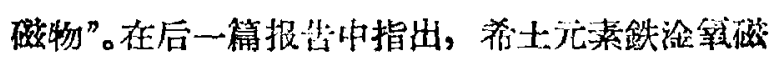

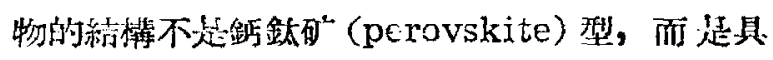
有 $\mathrm{Fe}_{2} \mathrm{Fe}^{\prime}{ }_{3} \mathrm{M}_{3} \mathrm{O}_{\mathrm{L}}$ 的一般形式的的顺榴石型, 其中

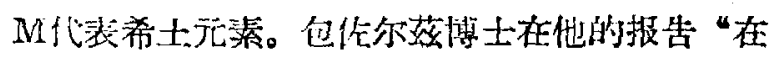

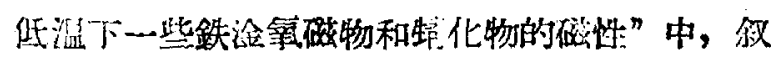

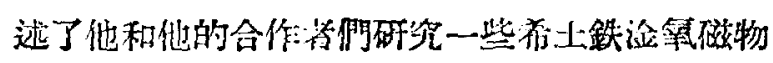
与有关化合物，以及一些鉄族堦化物从室洫遖到 $1.3^{\circ} \mathrm{K}$ 之間的柲化所得的結果。莫斯科的另洛夫

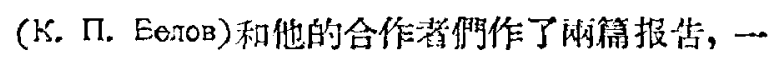

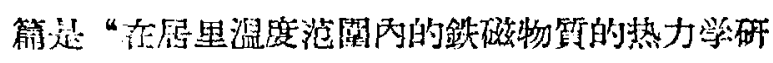

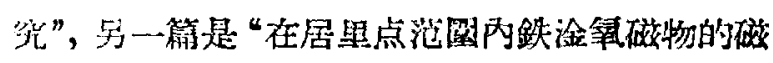
化的研究”。

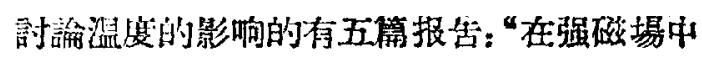

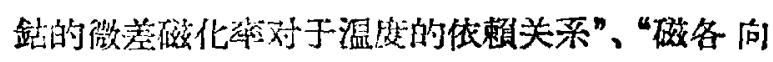

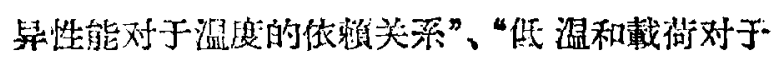
铁磁合金試枌“的飽和磁化强低的影响”、“錝的磁

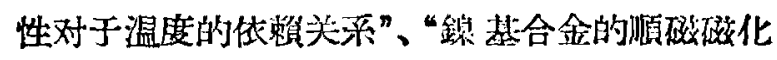
对于洫度的依赖关系”。

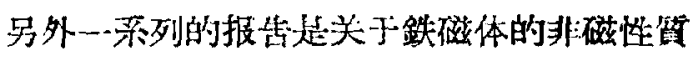
的。这种研究特别有兴趣，因为它們能綮使我们 对于物質的鉄磁态和反鉄磁誌的本性的看法这消 确奶，抹且能够說明周体的磁性与其它性算（电 的、热的、力学的等等) 之閒的联系的法則。这

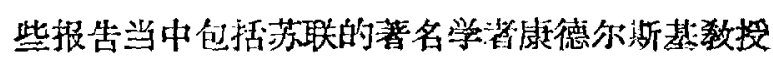
(Е. И. Конпорский，莫斯科大学物理系磁学研 室主任)、阿㡹洛夫教授(H. C. Axynos，白俄罗 斯共和国科学院院士）、和法基多夫数投（K. $\Gamma$. Факидов)等的工作。

法基多头和他的合作者报告了“硫化鉻的磁 性与电学性筫的关柔”，指出反鉄磁性的硫化鉻的

12月是

科学通报

- 67 . 


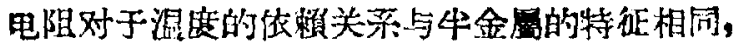
即电阻的温度系数在 $313^{\circ} \mathrm{K}$ 时忟号，但是鉄磁性 的硫化鉻的电阻温度系数却与金犀的特征相闰。 这表示在銑磁性的和反鉄磁性的硫化殓試样中的 电子能譲具有不同的本性。

康德尔斯基和他的合作者們作了雨篇报告。

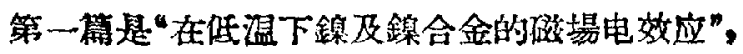

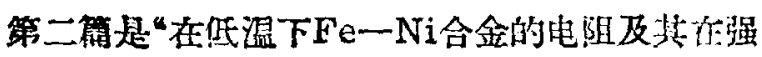
磁場下的变化”。第一篇研究了在温度 $2-4.2^{\prime} \mathrm{K}$ 和14-20.4 ${ }^{\circ} \mathrm{K}$ 䤼和 $\mathrm{Ni}-\mathrm{Cu} 、 \mathrm{Ni}-\mathrm{Cr} 、 \mathrm{Ni}-\mathrm{Mn}$ 合金的电阻势及其由于磁化到館和以后所起的变

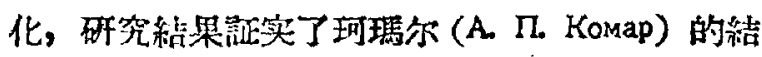
諭，即合金的有宗化与鉄磁佮中的磁埸电效应的 大小桶联系。第二䈐研究了在温设 $14-20.4^{\circ} \mathrm{K}$ 和63.15- $-92.2^{\circ} \mathrm{K}$ 会䤼 $40-93.3 \%$ 的鉄䤼合金的 电趾管及其由于瑅化而起的变化。

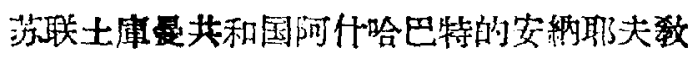

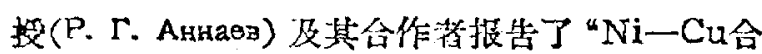
金系中的偶呚应和故效应的研究”。阿闻洛夫敉投 报告了“計筷毠晶体碰致伸縮的一种新方法”。符

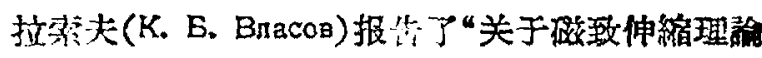
的几个間題”。

\section{4. 技术磁化曲和磁情枋料物理学}

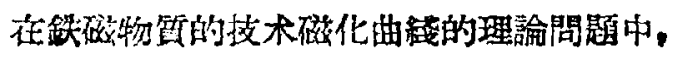
关于自磁化区域（磁瞦）的結搆的研究是通端

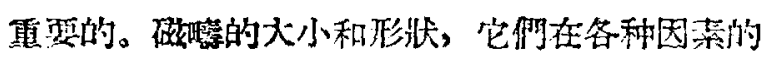
影响下产生和变化的条件，以及磁棝間界原的本

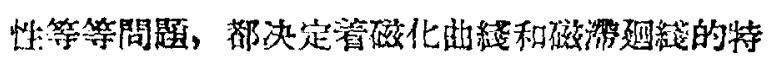

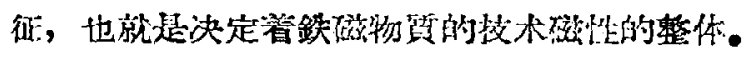
因此，在目前有很大的力步等中在磁瞚結構方面

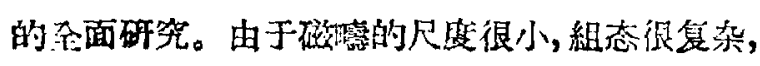

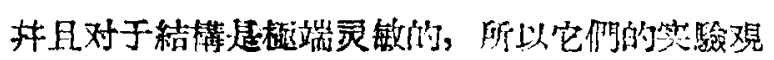
㴬很困难。

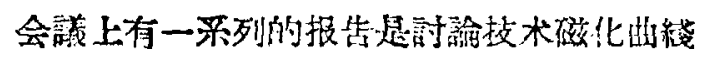
这个重㠫成题的。

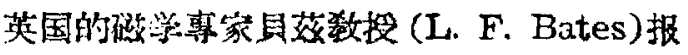
告了“关于留特圆 (Bitter figre) 的一些新实 驗”，在他的实驗室里研究了赫鉄晶体表面上的复 杂的枌末渴。借助于电子显殿鏡对于这些粉末圆

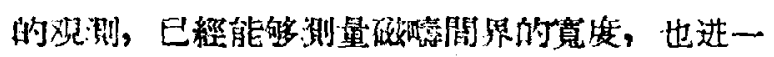

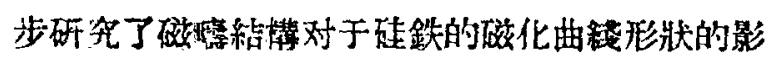
的。

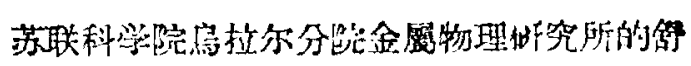

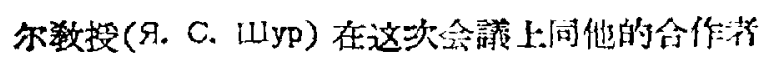

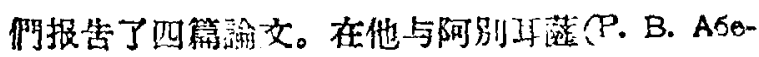

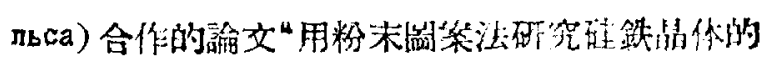

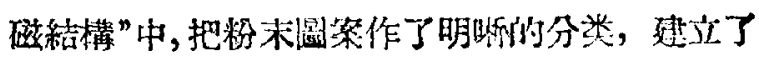

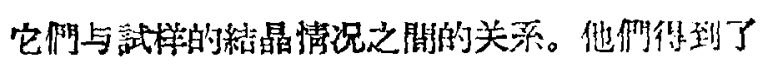

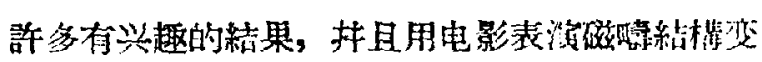

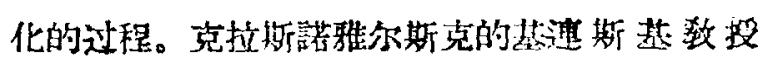

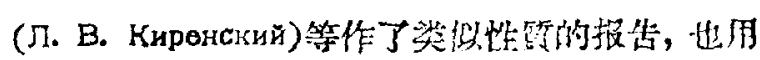

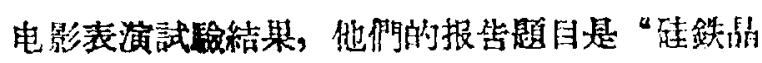

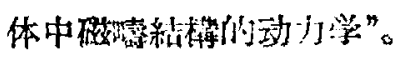

揵克斯泾伐克科学院物理研究所的卡朵尔

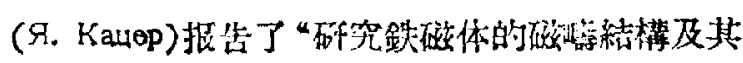

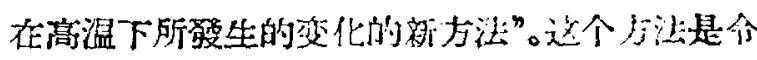

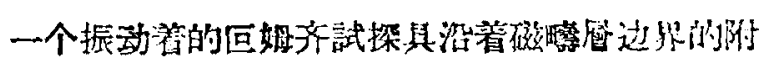

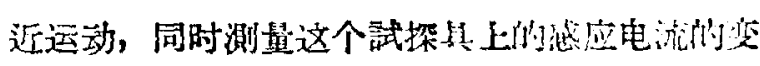
化。用这个方法所剆得的結果与枌不法所行的一

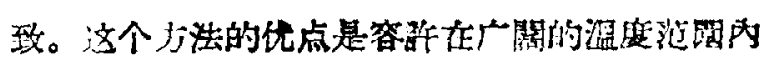

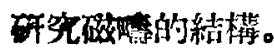

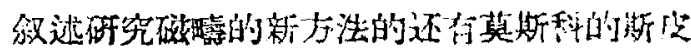

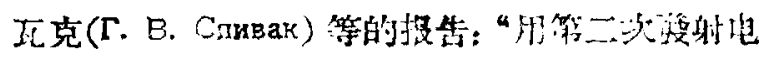

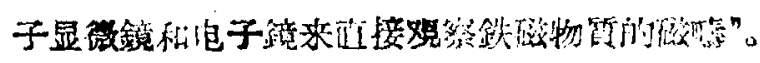

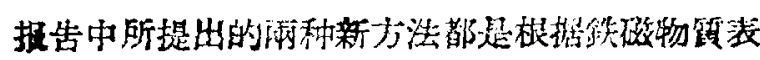

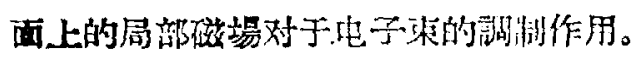

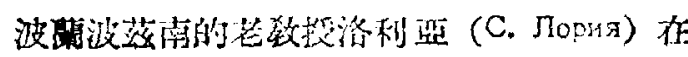

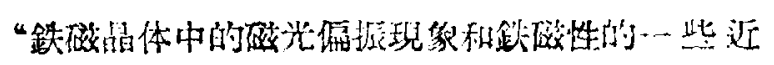

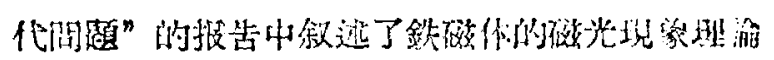

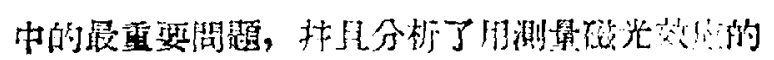

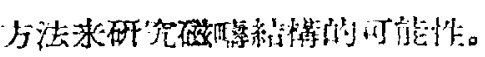

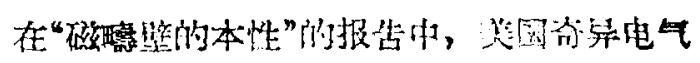
公司研究音的得年物理学家案恩(C. P. Bean)

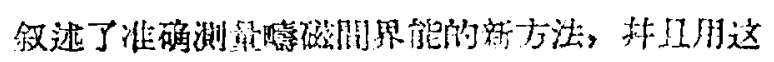

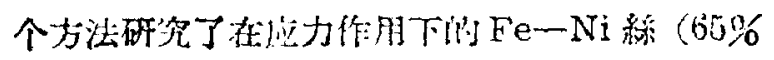

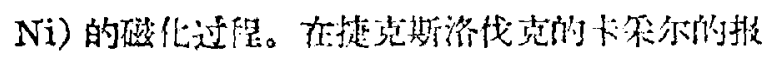

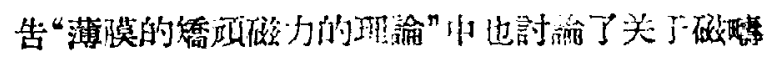

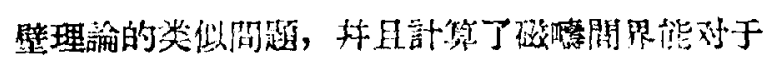
反磁化过稰的影响。

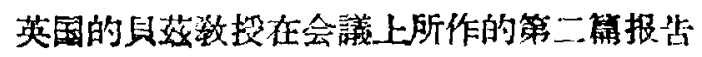
是“与磁化相跃系的热变化”。测量这种热变化的

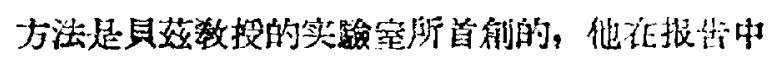
叙述了这种占法的新近改进, 特别是在弱磁場和 中等磁場的情形。在娜量这种热变化时, 若年类 
型的鉄涂氧硫物和珪鉄在弱磁場或無磁場时表現 了一种反裳的怒应。对于这种效应还浑有得到理 論上的解釋。

在会議上所作的关于碳性材料物理学的报告 包括以下各方面: 相轉变, 結晶織構和磁織構对 于鉄磁村料的磁性的影响，磁海現像，鉄磁体的 䂭粘帮性，以及硫性測量中的若干理論問題。

日本的久保完五教投报告了东京地区关于磁 学研究的一些新进盛, 这付括雨方面: 一方面是 过渡金盗及其合金在熔点温度下磁化究的变化， 一方面是指向有序所引起的磁各向异性。

舒尔教投与他的合作者們报告了“具有高稫 䛔磁力的磁場完向了的粉末样品的磁性”和“耕余 磁化了的顿磁物質的很結棈的稳定度”。

关于相罈变和結晶間題的报告有以下几篇: "Ni-Be 合金中的沉徒的研究"; 莫斯科斯大林鋼

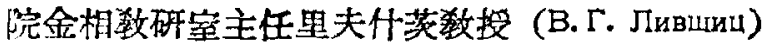
等的“Ni-周溶体在热处理时組織和性質的变化”、 “Fe-Ni-Al 合金在高矯磌磁力狀态下的組織”和 “用磁学方法研究 $\mathrm{Ni}_{3} \mathrm{Mn}$ 合金的有序化”; 杰赫 佳尔 (M. B. Дөxтяp)的“Fe-Ni-Mo 合金中的有

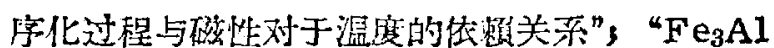
合金的有序無序轉变动力学”; “关于有序合金 $\mathrm{Fe}_{3} \mathrm{Al}$ 的磁性”。

下面的几篇报告致諭了反磁化的不可逆过程

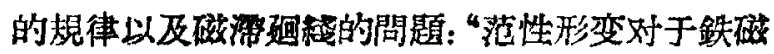
体中的柏克好楼效应的影响"; “鉄磁物質中反硫 化的不可逆跳变的研究"; “在轉动磁場中單晶鉄 磁体在相轉变以前和以后的磁漟建結的研究"; 基連斯基等的 “跌磁材料中的湜度磁溘和轉动磁

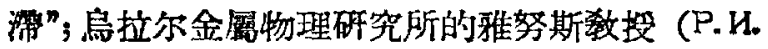

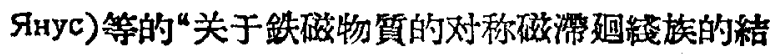
棈”。

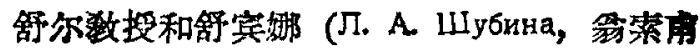
斯基通訊院士的夫人)等报告了“彈性应力及热机

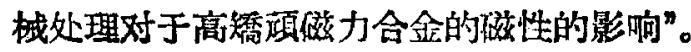

在蓦斯科的唗列斯宁 (P. В. Төлөснин) 等的 报告“ Ni-Zn 鉄的氧磁物在磁化的自由及强迫变 化中的磁粘滞性”中，领述了在 $78^{\circ} \mathrm{K}$ 到居里点的 温度范圆队各种成分和經过各种热处理的一系列 的 $\mathrm{Ni}-\mathrm{Zn}$ 鉄洽氧磁物在磁化的自由及强迫变化

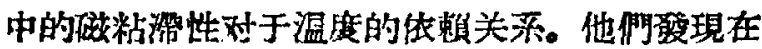

$78^{\circ} \mathrm{K}$ 时, 所有的陚样都具有超磁粘滞性, 粘㴆 性过程的期間达到几分鐘之久。

列宁格勒的怀耳(Ю. C. Вайль)报告了“关于 可逆磁导筞的减低”。

关于磁性測量物理学和仪器設訐問题的报告 有莫斯科的多尔根諾夫(C. Ш一. ДопгинОВ)等的“为

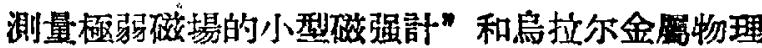
研究所的弗利德曼 (Л. X. Фридман) 同德罗仁娜 (B. U. Дрожжина，舒尔敉授的夫人)的“为剆量 小样品的性筫用的一种磁强計”。

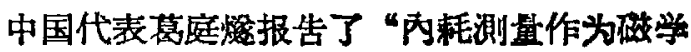
研究的一种方法”，在报告中叙括了在新中国的实 驗堂內所得到的与磁現象有关的內柜测蛋結果， 这包括三方面: (1) 关于淬硬鋼的镉碩磁力; (2) 关于鎳在交变效場中的磁化狀态（3）关于鉄中 磁政的运到及含碳的影响。

\section{二 等覌和活动}

\section{1. 苏联科学院物理問題研究所}

在会議开幕以前，苏联科学院招待玨会的外 国学者們参覌了物理問題研究所。所長卡皮㭗院 士不在莫斯科，由祖道院士和里甫西茨博士等接 待。他們首先介紹了該所的一般情况，所进行的研 究工作主要是低温物理学現像，其中包括液态痖 III和VI的超流动性，液态氦中的第二声效应，超

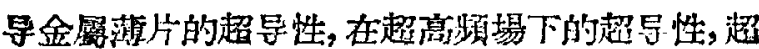
导合金的研究，压力对于超导体的“ $\lambda$ ”点的影响, 在低湿度下 $\left(<1^{\circ} \mathrm{K}\right)$ 的比热; 倾磁性和反鉄磁性。

参覌以后㷅由師道院士解答了許多問題。殿 所是 1934 年侴建的，最近正在大規模扩沦中。

\section{2. 莫斯科大学物理系磁学实驗蜜}

中国代表团 3 人在会議閉幕后参观了莫斯科

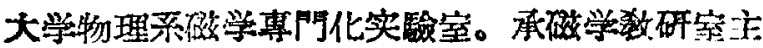
任康德尔斯基钽援解与說明。首先参观了三、 四年数率業实驗室，包括: 用各种不同的方法测量 磁場（冲击法、質子共振浩等），静电磁强計，無 定向磁强計，彈性張应力对于鉄磁物算的磁性的 影响，“磁各向异性常数的測 量 (轉矩法)，磁 感

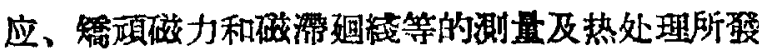
生的影响, 变压器圈的椇耗, 磁致伸繀的测量, 各种精滵測量例如篗耳效应的测量等。

据中国留学生嫩，磁学数研空一共有 20 几个 
研究䇪。由于时間的限制，我們只参覌了一部分。 沃尔柯夫博士 (ㄱ. H. Borк08) 的研究室里正在研 究鉄磁物質在居里点附近的磁性，这包括磁化本

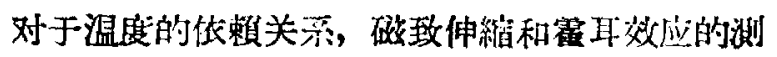
量等。克林契克溥士（Г. C. Кринчик）的研究察 里正在研究在磁媒留中的克尔效应。另一个研究

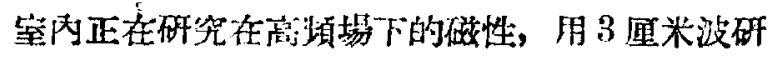
究在磁埸下倨振泊门轉动(法拉第交应)。还有一

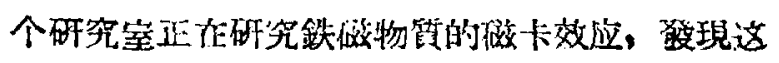
种效应与温传和磁場柯关系。

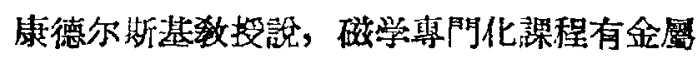

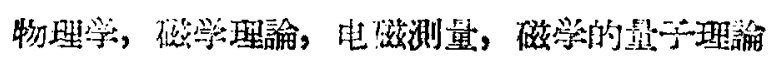

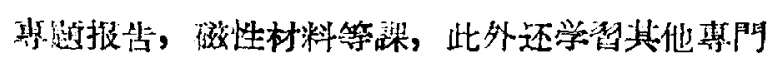
化的等業湫程如电磁齐, 統計物理, 热力学等。

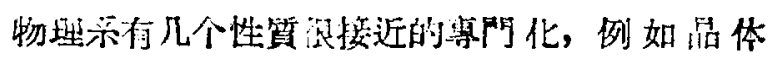
学、X光与金屬物理、磁学、牛导体等，它們繶

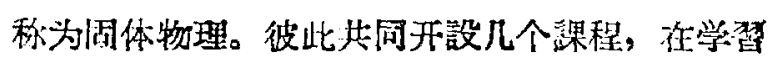
上和研究工作的进行上可以收到同工合作之效。

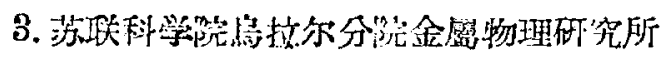

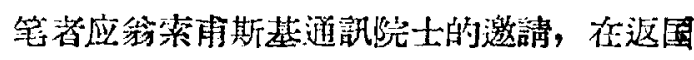
这中到斯維尔德洛夫斯克的金闻物理研究所参观

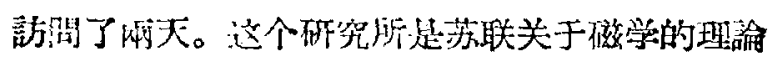

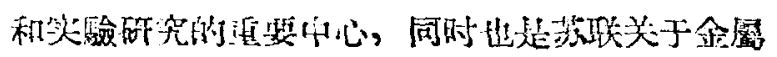

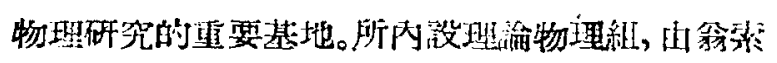

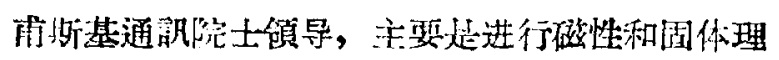

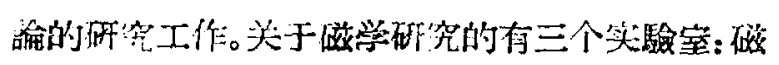

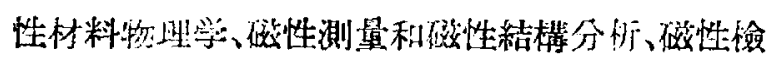

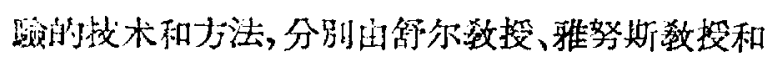

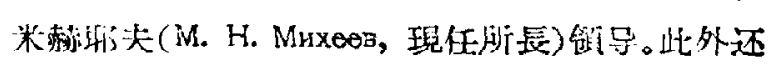

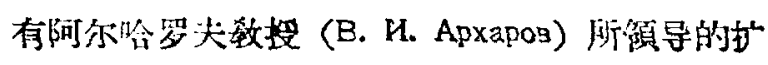

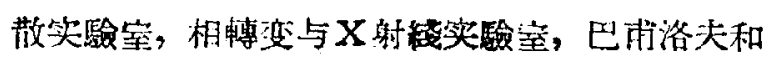
雅科甫列娃 (В. А. Павлов、Е. С. Я ковлева) 所

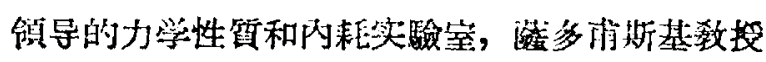
(B. Д. Саповсиий) 所㥧导的金相学实驗空, 电

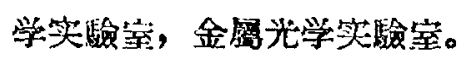

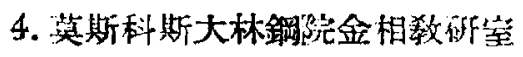

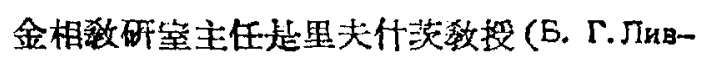
шиu)，在这次会議上他同他的合作者报告了三篇 論文, 都退关于磁性材料方面的。实驗空的主要研 究方向是关于各种鉄䂭性合金 (主要为 $\mathrm{Ni}$ 合金) 的脫溶与时妓問题，特別注意起始的阶段。实驗

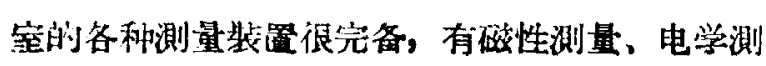

量、硬度测量、膨做測量、徨工效应測量等装

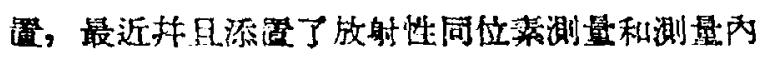
耗的拝摆装留。

\section{5 . 其它}

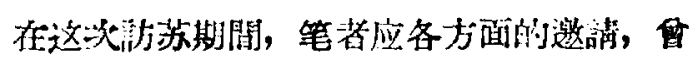

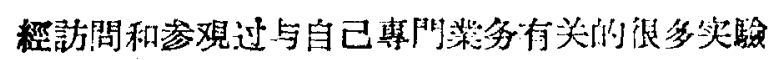

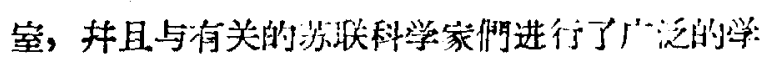

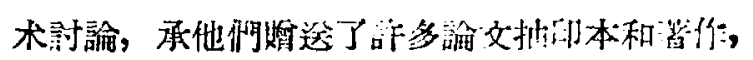

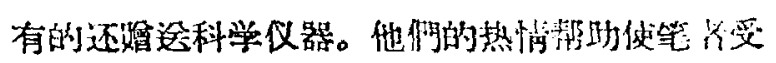

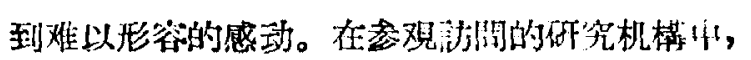

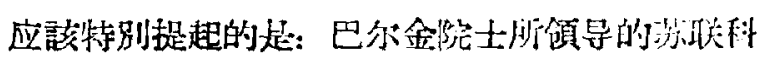

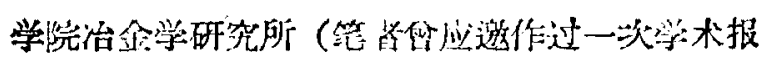

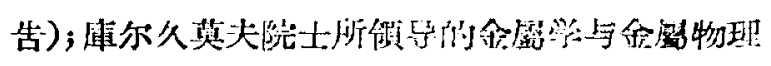

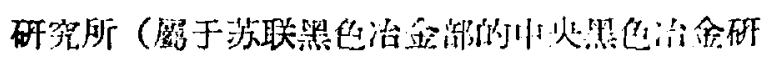

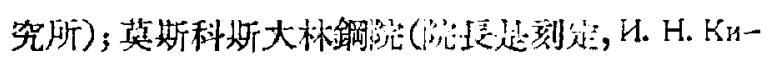

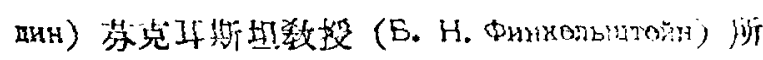

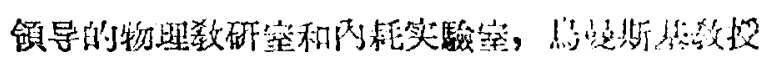

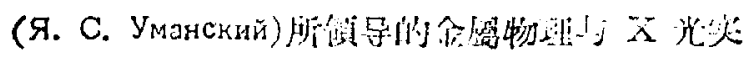

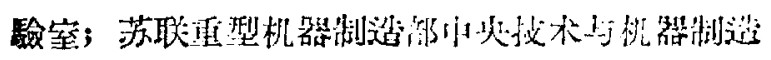

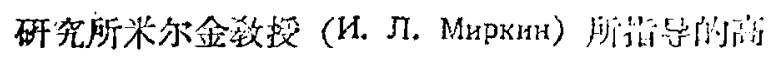

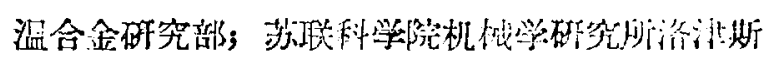

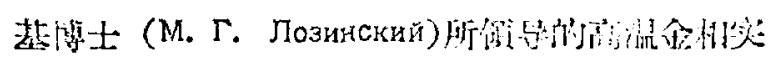

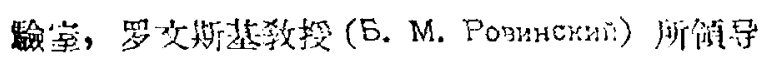

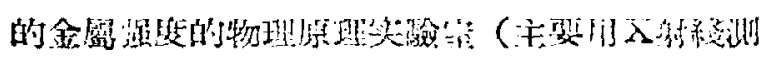

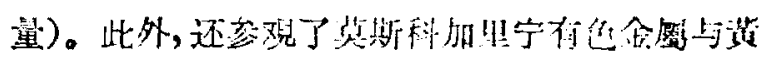

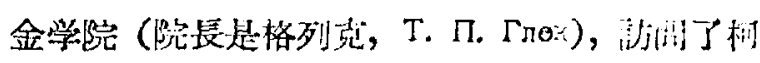

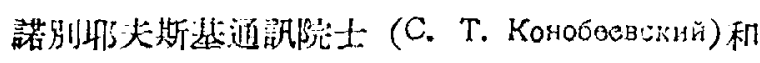
他的合作者普拉得久拄( (Н. Ф. Правдюк)。

\section{三几点伀会}

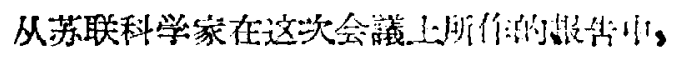
可以看出苏联近年来在磁学及其有沃方湎沂获得

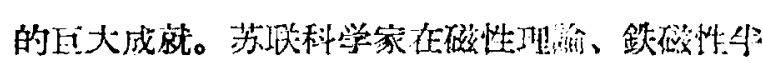

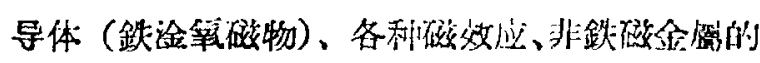

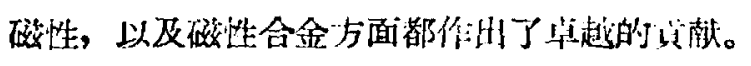

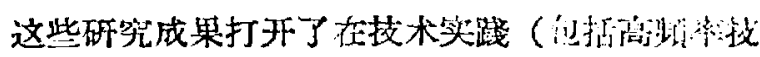

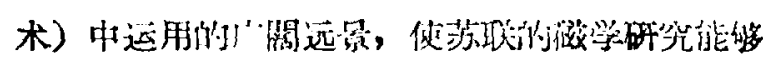

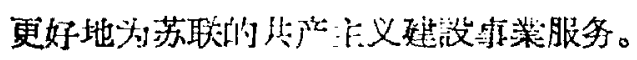

在这次会議上，各国的科学策何进行了交好

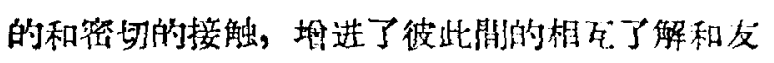
誼。同时，与会的外国科学傢们在然地的观等当 中，也就能够亲车体驗到苏联科学的优越威就和 
苏联的社会制度的，本質。苏联科学家們对于外国 科学家們所作的报告是非常重視的, 每次报告完

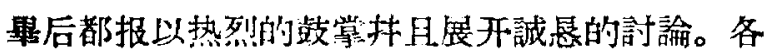
国的科学家们在这种相互盆重、相互友好的气氛 当中, 便当然而然地境养和建立了彼此之間的情

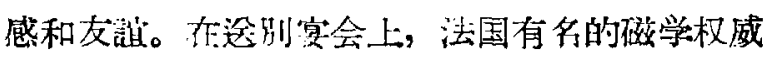

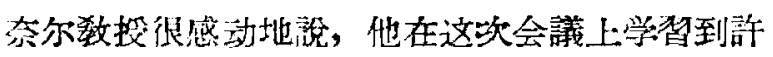
多他过去不知近的手酒。美国的著名的包左尔䓋

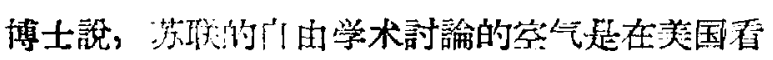
不到的。侕蘭的戈特教授說，鉄䂭性現象中的主

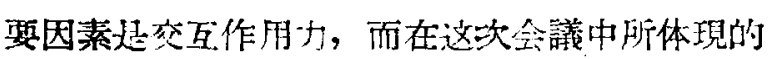

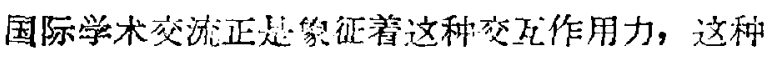

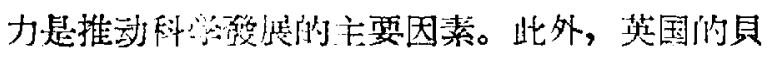

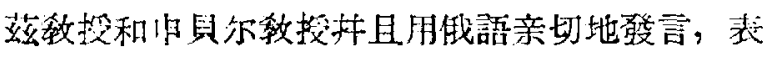
达他們对于主人的热情招待的鼓心謝意。伍客会 上宾主交㳄们情形是十分令人感动的。

在会議湖中，中国代表伐除去问苏联和备人 民民主国家的科学家們进行亲切的討論和学得以 外，还同資本主义国家的科学家們进行了广泛的

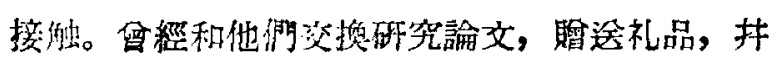

且介稆了新中国科学研究的情况, 討諭了术白 由、科学研究的目的性和計划性、思想改造、培 养科学干部的方式方法和科学家的鉃研动力等問 題。在这些接触和交談当中，科学家們之閒的自

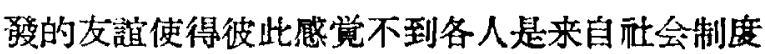
不同的国家的。

正如籍觉甫斯基通到院士在会議閉幕詞中所 說的: “虽然公議的日程很紧張, 但是找們的客人 和苏联科学家利用了每一分鐘的时間 来討諭問 题，交撸意罗。这种無拘無束的环境粭今后进一 步的合作勇定了良好的基础。在会场中所洋溢着 的相互尊重和相互爱护的气氛使我們确信我佃之

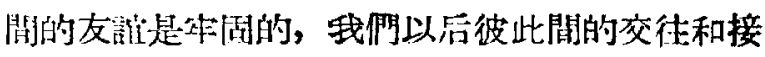
蚛将是經常的, 这將不断地推动磁現象物理学的 进一步發等, 使科学能够更好地为人正的利益服 务。”

附記: 这篇报告脫稿后, 冓中国科学 院应用物理研究所磁学組潘孝碩等同志校 閶，㯵此志謝。

\title{
訪問苏联科学院远东分院
}

\author{
吴 傅 鈞 \\ (中国科学院地理研究所)
}

今年七、八月問，笔者曾老加中苏合作黑龙江 綜合拷察工作，得有机会汸問苏联完东地区海策 泡、列宁斯克、伯力、敏参崴等地, 种荅覌了苏 联科学院远东分院。茲据所見所闑对該分院情况 简要报导如次, 以供我国科学工作的参考。

苏联科学院远东分院是以前任院骎、已故地 植物学㒸B.Л. 柯瑪洛夫院士的名字命名的。該院 涂立于 1932 年, 迄今已有 25 年历史。現任院長 是化学博士B.T.白柯夫。近 10 年来, 积極調配力 量, 大組樴, 發展很快。1945年时分院內部仅 有 3 个学科維, 到目前已有 12 个学科組和 27 个 实擥室, 工作人員亦比10年前增加了 3 倍, 是远 东地区一支强有力的科学队伍。

远东分院是一个棕合性的科学研究机構, 10
年来根据各䙺輀求和地方秝济文化原有基础和特 点, 先后成立了 12 个学科組。其中在 1949 年以 前成立的有: 地質組、化学組、动物組、植物組、 原始林保留地和圖書館; 在1953年以前成立的有 永能䋎、船济組、植物园、植物化学与生理組、 第一（数理）实騟空，以及山林站，在1953年以 后成立的有历史与考古組。

地質組主任为 $M . \Gamma$. 奥却諾夫博士，組队分岩 不、矿物、地球化学等小組, 因形势耶展需要, 明年可独立成研究所。該組对远东地区金矿有詳 細研究，在岩石研究方面应用光諧分析等力法。 研究成果除公开任版刊物外，还们行一种內部全 考資料。

化学組主任由分院院長白柯夫博士策任, 組 